Ciencia y Educación, Vol. 5, No. 2, mayo-agosto, 2021

ISSN (impreso): 2613-8794・ISSN (en línea): 2613-8808

DOI: https://doi.org/10.22206/cyed.2021.v5i2.pp41-62

\title{
Estrategias para el desarrollo de la competencia lectora. Una propuesta metodológica
}

\author{
Strategies for Developing Reading Literacy. A Methodological Proposal \\ María Elena Michael Pérez Medinaa ORCID: 0000-0002-5780-796X \\ Esperanza Lozoya Meza ${ }^{\mathrm{b}}$ ORCID: 0000-0002-0265-7271
}

Recibido: 06/08/2020 • Aprobado: 30/11/2020

Cómo citar: Pérez Medina, M. E. M., \& Lozoya Meza, E. (2021). Estrategias para el desarrollo de la competencia lectora. Una propuesta metodológica. Ciencia y Educación, 5(2), 41-62. https://doi.org/10.22206/cyed.2021.v5i2.pp41-62

Resumen

El propósito de este artículo es presentar una propuesta de estrategias metodológicas que contribuyan al desarrollo de la competencia lectora, basadas en la educación Ciencia, Tecnología, Ingeniería, Artes y Matemáticas (CTIAM), para la formación de lectores en el contexto educativo mexicano. Es un estudio de tipo cualitativo en el que se realiza una revisión bibliográfica sobre la competencia lectora y la educación CTIAM. Se presenta una propuesta metodológica que tiene como elementos centrales la interdisciplinariedad, la contextualización, la actitud crítica y la lectura digital. Se señala, además, la posibilidad de diversificar las estrategias de enseñanza de la competencia lectora mediante su relación con otros campos formativos. A partir de los resultados obtenidos, se aporta una estructura de estrategias como alternativa para la formación de lectores competentes en aras de una alfabetización funcional.

Palabras clave: competencia lectora, método de enseñanza, CTIAM, alfabetización funcional.

\begin{abstract}
The purpose of this article is to present a proposal of methodological strategies that contribute to the development of reading literacy based on education Science, Technology, Engineering, Arts and Mathematics (STEAM), for the training of readers in the Mexican educational context. It is a qualitative study in which a bibliographic review is carried out on reading literacy and STEAM education. A methodological proposal is presented that has as its central elements interdisciplinarity, contextualization, critical attitude and digital reading. It also points out the possibility of diversifying the teaching strategies of the reading literacy through its relationship with other training fields. Based on the results obtained, a structure of strategies is provided, as an alternative, for the training of competent readers for the sake of functional literacy.
\end{abstract}

Keywords: reading literacy, teaching strategies, STEAM, functional literacy.

\footnotetext{
a Centro de Investigaciones Económicas, Administrativas y Sociales (CIECAS), México. Correo-e: mperezm1700@alumno.ipn.mx

b Instituto Politécnico Nacional, México. Correo-e: elozoyam@ipn.mx
} 


\section{Introducción}

Desde los enfoques teóricos de la lectura es posible distinguir tres maneras en cuanto a su tratamiento: por un lado, desde la enseñanza, se aborda como objeto de estudio; por otro, se observa como actuación; y, desde otro punto, como resultado de la creación de conocimiento.

Esta investigación parte de estas maneras de mirar la lectura al reconocer que desde la enseñanza funge como una competencia básica dentro del modelo educativo por competencias, adoptado por México dentro de su currículo educativo oficial. Como actuación, al pensar en un lector crítico, el cual logra recuperar inferencias, distingue diferentes significados, lee de manera distinta cada género (Cassany, 2008), en diversos soportes, se apropia del texto y le otorga diferentes usos. Y, al remitir a un carácter epistémico, al ser la lectura fuente en la construcción de conocimiento propio (Solé, 2012).

Sin embargo, estas tres perspectivas apuntan a que actualmente no existe un consenso en cuanto al abordaje de la lectura, lo cual se traslada en un reto ante lo que se nombra como sociedad del conocimiento, donde los distintos formatos en los que se despliega el código escrito, como la lectura digital, señalan cambios en su apropiación y uso. Asimismo, las constantes innovaciones científico-tecnológicas, que caracterizan a dicha sociedad del siglo xxI, instan a una reconceptualización de la lectura y por ende a una didáctica que involucre prácticas orientadas a formar lectores competentes.

En el caso de México, el Plan Nacional para la Evaluación de los Aprendizajes (PLANEA), aplicado por la Secretaría de Educación Pública (SEP) en estudiantes de nivel básico, señala, para el año 2017 en el área de lenguaje y comunicación, que más del 70\% de la población se ubica en los dos niveles básicos que equivalen al dominio insuficiente y básico de los aprendizajes: el 40.1\% de la población estudiantil, de tercero de secundaria, se ubicó en el nivel II y el 33.8\% en el nivel I (INEE, 2017).

Asimismo, el reporte sobre el módulo de lectura que realiza el Instituto Nacional de Estadística y
Geografía (INEGI) indica que ha disminuido la población lectora en México entre las personas mayores de 18 años, con relación al año 2015, donde el 84.2\% declaró haber leído algún material de lectura (libros, revistas, periódicos, historietas y publicaciones digitales); mientras que en el año 2018 se reportó el 76.4\% (INEGI, 2018, p.1). Por otra parte, este informe señala que, aunque se sigue prefiriendo la lectura del material impreso, el porcentaje correspondiente al uso de material digital se incrementó el doble durante el mismo periodo.

A nivel internacional, el Programa para la Evaluación Internacional de los Estudiantes (PISA, por sus siglas en inglés Project for International Student Assessment) se reconoce como un instrumento de evaluación de competencias, entre las que se encuentra la lectura. En esta prueba se encontró que México ha mantenido un puntaje mínimamente variable, en los años dedicados al área de lectura: 422 puntos, en el año 2000; 425 puntos, en el año 2009 y 423 puntos, en el año 2015. Es decir, solo ha obtenido una ligera variación de tres y dos puntos, sin lograr un incremento substancial (OCDE, 2015). Cabe señalar que ese puntaje se encuentra dentro de los niveles bajos del promedio, ya que el máximo suele estar arriba de los 550 puntos.

Estas cifras apuntan a aquello que señala Reimers (2006) acerca de que la culminación de la educación básica no es suficiente para que los sujetos educativos puedan desarrollar la competencia lectora con efectividad en una sociedad basada en el conocimiento. Bajo esta idea, Reimers advierte que, en el caso de México, los planes y programas sobre competencia lectora deben considerar estándares más exigentes para lograr mejores resultados puesto que, en la planeación, se dispone alcanzar los niveles medios, los cuales ha conseguido un reducido número de la población, sin lograr la eficiencia.

Dentro de este panorama, se observó como problemática que los resultados de pruebas nacionales e internacionales relativos a la competencia lectora muestran la necesidad no solo de mejorar el índice de resultados en la población estudiantil, sino de contribuir en los 
estudios de investigación y formación para constituir una sociedad de lectores competentes.

Por lo anterior, se plantea la tarea de elaborar y diversificar estrategias (Solé, 2012) a favor de la enseñanza y el aprendizaje de la competencia lectora a través de intervenciones específicas que involucren distintos ámbitos disciplinarios. En este sentido es que se entiende por estrategia "el elaborar planes tendientes al logro de una meta” (Ángulo, 2017, p. 185), es decir, la creación de un plan de acción para el desarrollo de la competencia lectora dentro del contexto educativo mexicano que, sumado al aspecto metodológico, contemple "procedimientos, recursos, criterios, técnicas y normas prácticas que permiten sistematizar y construir un método que, bajo razones pedagógicas, responden a situaciones didácticas." (Ángulo, 2017, p. 270).

En esta investigación se propuso la creación de estrategias metodológicas para el desarrollo de la competencia lectora basadas en elementos de la educación CTIAM (Ciencias, Tecnología, Ingeniería, Artes y Matemáticas), en inglés Science, Technology, Engineering, Arts y Mathematics, el cual deriva de STEM, que por sus siglas se traduce como Science, Technology, Engineering y Mathematics; y que para efectos de este artículo se habrá de señalar como CTIAM.

Este modelo se basa en un enfoque interdisciplinario del proceso de enseñanza y aprendizaje que incorpora contextos y situaciones de la vida cotidiana y utiliza herramientas tecnológicas, con énfasis en las áreas mencionadas.

Dentro de los trabajos que evidencian la vinculación de la lectura con la educación CTIAM se encuentran el de Yakman y Lee (2012), al integrar las artes del lenguaje; Lewis (2015), al destacar el papel de las humanidades en CTIAM; la reflexión de Baines (2015), la cual señala la importancia de la enseńanza del lenguaje en la alfabetización del siglo xxi; en todos ellos se reconoce a la lectura como conocimiento fundamental. Mientras que el trabajo del Institute for Entrepreneurschip in Education Caster Family Center for Nonprofit and Philanthropic Research (2017) ofrece un recuento de aplicaciones como producto de estrategias que desarrollan la competencia lectora mediante textos vinculados con temas de las disciplinas que comprenden la educación CTIAM. Fue así como surgió como pregunta de investigación: ¿Cuáles elementos teórico-metodológicos se necesitan para elaborar estrategias que contribuyan al desarrollo de la competencia lectora, basados en educación CTIAM, a fin de lograr una alfabetización funcional?

La idea de alfabetización funcional alude a la finalidad que Yakman y Lee (2012) señalan para la educación CTIAM al procurar habilidades de aprendizaje permanentes que respondan a las necesidades académicas del siglo XXI. Lo anterior converge con el modelo educativo por competencias al considerar que estas habrán de desarrollarse a lo largo de la vida (SEP, 2011b). En este sentido, la alfabetización representa, en palabras de Ángulo (2017): "un continuo de aprendizaje que permite a un individuo alcanzar sus metas, desarrollar su conocimiento potencial y participar plenamente en la comunidad y la sociedad en general" (p. 38). Al ser funcional, no solamente se remite a una actuación o comunicación eficaz sino, también, al empleo del código escrito junto con la tecnología, lo que Moreno (2008) considera como una segunda alfabetización que insta a una reorganización de las competencias adquiridas.

Ante lo antes planteado, como supuesto de esta investigación, se señala que la metodología CTIAM puede contribuir al desarrollo de la competencia lectora en México mediante el diseño de algunas estrategias metodológicas con la finalidad de proponer un andamiaje para futuras aplicaciones educativas.

Para tal fin se realizó una revisión de los elementos que conforman la competencia lectora y aquellos que corresponden a la metodología de la educación CTIAM, lo cual tiene sustento en el marco teórico, situado desde el enfoque del socioconstructivismo y desde la visión sociocultural sobre la lectura. Para el análisis de la información se utilizó un método de triangulación y categorización a fin de obtener los elementos que dan pie a la construcción de las estrategias. 


\section{Referente teórico}

Como fundamento para la definición de la competencia lectora para este trabajo se retoma la visión de la perspectiva sociocultural o sociolingüística, la cual considera a la lectura como un ejercicio inferencial con un propósito comunicativo, donde destaca el objetivo y fin del lector, así como la intencionalidad del autor. Desde este enfoque la alfabetización es vista como un acto determinado culturalmente por lo cual se centra en el contexto y en las formas de utilización de la lectura -así como de la escritura- por parte de los sujetos (Rodríguez, 2004).

Desde este pensamiento, la investigadora Solé (2012), en su monográfico dedicado a la competencia lectora, califica a esta como una concepción amplia y compleja que tiende hacia la alfabetización individual y social. En su postura manifiesta dos ideas: en la primera idea señala que la noción de lectura y de las formas de ser lector son definidas por cada época, en donde existen diferentes códigos, usos y funciones. Aunado a ello, sostiene que leer no es una capacidad única e idéntica que se aprenda de una sola vez durante un ciclo o nivel de estudio, sino que considera que su adquisición y dominio habrá de ocurrir durante toda la vida

En la segunda idea, Solé insta a la descripción de este concepto como multidimensional y complejo, en contraposición a la visión que se concibe como tradicional y que define a la competencia lectora como un hábito del lenguaje o conjunto de subhabilidades. Propone una visión amplia sobre la lectura, donde en su complejidad se contemplen la confluencia de componentes emocionales, cognitivos y metacognitivos; estratégicos y automáticos; e individuales y sociales. Y que, en la parte multidimensional, se movilicen las capacidades cognitivas, afectivas y de inserción social para así lograr su uso y apropiación.

Para dicha investigadora la lectura como competencia contribuye a formar otro tipo de lectores, esto es, usuarios competentes y críticos de los textos, en el formato en que estos se presenten (Solé, 2012).
Al respecto, Makuc (2011) apunta que un lector competente será considerado como experto en la medida en que distinga más allá del ámbito de la comprensión y se piense en este concepto como un complejo de múltiples procesos en el cual tiene incidencia la experiencia del propio lector y los modelos culturales.

Bajo esta concepción, Solé (2012) juzga necesario diversificar las estrategias y situar ámbitos disciplinares distintos en la enseñanza y el aprendizaje de la competencia lectora, puesto que considera que esto conducirá a tratar con las convenciones específicas de los textos, que son propios de cada área, y con ello aumentar la capacidad crítica de los estudiantes, ante lo cual habrán de realizarse situaciones significativas y retadoras de lectura.

Por su parte, Cassany (2005, 2006, 2008, 2010, 2012) rechaza el concepto de competencia lectora y en su lugar promueve la idea de la lectura como una práctica social que se relaciona con otras prácticas de este tipo (como trabajar) y que se integra con otras destrezas lingüísticas (el habla, producción escrita, entre otras).

No obstante, Cassany, al igual que Solé, señala que en la actualidad leer se ha vuelto más complejo, por lo cual se requiere una actitud crítica ya que se presentan más variables de comprensión (como el idioma o el lenguaje de especialidad). Cassany (2008) encuentra que las nuevas maneras de leer implican distintas formas de representación (como la fotografía, el vídeo o las simulaciones virtuales); en las cuales observa que, actualmente, se lee más y de manera diversa y se puede acceder a textos de distinta procedencia, sin ejercer un control de calidad.

En consonancia, Riascos y Valverde (2018) coinciden con Cassany acerca de la convergencia de las concepciones teóricas tradicionales sobre la lectura y la perspectiva sociocultural para una mejor formación y didáctica; en su estudio sobre la lectura crítica concluyen que:

debe ser enseñada a partir de la planeación de estrategias y secuencias didácticas que permitan a 
los estudiantes avanzar de los elementos iniciales a los más complejos (...) con sus diferentes niveles, literal, inferencial, crítico-intertextual, sin olvidar que las estrategias pedagógicas y didácticas deben ser integrales, respondiendo a todos los ámbitos del desarrollo de los estudiantes, y no encasillarse en el área o asignatura de la lengua castellana, pues la lectura es interdisciplinaria y transversal. (p. 90)

En lo que se refiere a la evaluación de la competencia lectora, destaca la labor de PISA, quien ha emitido dos reflexiones teóricas: una, en el año 2009; y, otra, en el año 2018; esta última se distingue por hacer una recapitulación de los cambios en su definición y emitir una actualización del concepto.

En principio, PISA señala que el término "competencia" es el más adecuado, puesto que define la "capacidad de un individuo para aprender, usar y comunicar información escrita e impresa" (OCDE, 2018, p. 10) ante distintas situaciones y para diversos fines. Bajo esta visión se incluye tanto las competencias cognitivas y lingüísticas, que van desde la decodificación, la gramática y la comprensión; así como las metacognitivas, que refieren a la reflexión sobre el acto de la lectura.

PISA considera las habilidades de comprender, usar y evaluar. Al referirse a la comprensión refiere a "la integración de la información del texto con las estructuras de conocimiento del lector" (OCDE, 2018, p. 11); el uso tiene que ver con la aplicación y función de lo que se lee; evaluar señala lo que el lector es capaz de analizar y descubrir la "veracidad de los argumentos en el texto, el punto de vista del autor y la pertinencia de un texto en relación" (OCDE, 2018, p. 11) con sus objetivos. El "reflexionar sobre" se agregó en la nueva definición y se piensa como la reflexión que se hace sobre la información textual y extratextual, en la cual se involucran los conocimientos previos del lector, así como sus intereses y habilidades.

En esta definición se pugna por el compromiso, con lo que alude a la motivación e interés por la lectura, el comprender características afectivas y conductuales que tienen que ver con el gusto y control sobre el tipo de textos que se lee.

Ahora bien, la prueba se realiza a partir de tres dimensiones que explican los procesos de lectura: lector, texto y tarea o propósito. De esta manera, en el contenido del instrumento se piensa en distintos materiales -manuscritos, impresos o digitales-, escenarios, contextos y fines; en lo cual se observa la influencia teórica sobre la importancia del contexto y el propósito de la lectura.

Con respecto a la lectura digital, Cordón y Jarvio (2015) señalan que la tecnología modificó la estructura y lectura habitual del texto impreso, lo cual produjo que la disposición del texto fuera más sencilla, fácil de obtener y transportar. Para estos autores, el hipertexto, elemento que caracteriza a la lectura digital, cambió la forma en cómo se recibe y organiza esta información, puesto que a través de este el lector se conduce por la lectura a saltos, mediante palabras, imágenes y sonidos. Con relación a lo anterior, Trillos-Pacheco (2013) señala que la lectura digital puso de manifiesto la convergencia de la competencia lectora con el despliegue de competencias tecnológicas.

Ahora bien, en el sistema educativo mexicano se observó que la definición y evaluación de la competencia lectora ha tenido preeminencia en los primeros niveles educativos por asumir la enseñanza de la lectura como parte de la alfabetización inicial, al considerar que es en ese periodo donde los estudiantes habrán de adquirir las competencias básicas para después emplearlas en los niveles superiores.

En México, la adopción del modelo educativo por competencias añadió la enseńanza y evaluación de la competencia lectora, desde el año 2011, para la educación básica (primaria, secundaria y educación media). No obstante, se encontró que su valoración en los documentos de certificación guarda un carácter no formal.

En el nivel de primaria y secundaria se halló que, inicialmente, se admitió para su evaluación las habilidades de velocidad, fluidez y comprensión, de las cuales se asumió un proceso progresivo (SEP, 2011a). 
De esta manera, las autoridades educativas aplicaron una metodología basada en la intervención del docente para evaluar el nivel de logro de los tres factores. Posteriormente, en el año 2013 se renovó el concepto y se determinó que la evaluación de la lectura correspondía a su uso como herramienta de aprendizaje (SEP, 2013) así como a su constitución como competencia, entendida como comprensión lectora, ante lo cual se retomó la visión teórica de PISA.

Mientras que, en el nivel medio superior se encontró que, si bien inicialmente no se especificó la enseñanza de la competencia lectora, posteriormente, en el documento del Modelo Educativo para la Educación Obligatoria (SEP, 2017) sí se hace. Allí se describe como una competencia habilitante, lo que indica habrá de mantener una actuación transversal, es decir, se promoverá en todos los campos de conocimiento y disciplinas por su importancia significativa en cualquier tipo de aprendizaje.

Por lo que refiere a la educación superior, las investigaciones de Sánchez y Sánchez et al. (2009 y 2011, como se citó en Bañales et al., 2013, p. 172) señalan que los estudiantes de este nivel presentan problemas para realizar procesos de comprensión inferencial y crítica. En consonancia con el perfil de egreso que poseen los estudiantes al terminar cada nivel de la educación básica, en tales trabajos se halla que las habilidades de la competencia lectora que se espera de los egresados sea en correspondencia al nivel de escolaridad; por ejemplo, para bachillerato: "análisis, crítica, deducción lógica; licenciatura: memorización, síntesis, interpretación, crítica; posgrado: establecimiento de vínculos intertextuales, análisis, síntesis crítica, razonamiento lógico y argumentación” (Bañales et al., 2013, p. 170).

En lo que corresponde a la educación CTIAM, destaca la aportación de la investigadora Yakman, quien propone una estructura donde todas las disciplinas se relacionan entre sí con el propósito de desarrollar habilidades de aprendizaje permanentes basadas en lo que denomina alfabetización funcional. Esta idea la asocia a los cambios científicos-tecnológicos e intenta responder a las necesidades de formación académica que se requieren en el presente siglo.

De esta manera, desde el punto de vista de Yakman, se espera que los estudiantes que se formen bajo esta perspectiva sean personas funcionalmente más instruidas y efectivas puesto que aprenderán a leer y escribir en cada campo y entenderán, además, las conexiones que se establecen entre las disciplinas (Yakman y Lee, 2012).

Es decir, Yakman no descarta las competencias específicas, sino que, considera es posible integrarlas desde la construcción mental a otros campos, a través de una relación interdisciplinaria. Encuentra además que todo esto constituye, a su vez, un aprendizaje de por vida, que reditúa en una mejor comunicación con los otros (provenientes de otras áreas, perspectivas y culturas).

Ahora bien, al proponer la suma de las artes al concepto de educación CTIAM, Yakman considera las del lenguaje, sociales, físicas, las bellas artes, las plásticas y las manuales. Las del lenguaje son para esta autora aquellas que proporcionan una comunicación efectiva (Yakman y Lee, 2012). Su importancia resulta vital para cada disciplina, puesto que contribuyen a expresar y comunicar los conceptos, las teorías y los diseños. En este sentido, esta autora admite el uso de las competencias comunicativas para el manejo de vocabulario, la comprensión de conceptos y teorías, así como para una transferencia eficiente del conocimiento.

Con relación a la metodología utilizada en la educación CTIAM, se observó el reconocimiento de distintos métodos de aprendizaje que propician a su naturaleza como un enfoque integrado (Capraro y Morgan, 2013, como se citó en Liao, 2016), el cual se caracteriza por una relación interdisciplinaria con énfasis en sus aplicaciones en el mundo real (García et al., 2018). Asimismo, el despliegue de su metodología hace uso de las Tecnologías de la Información y Comunicación (TIC), bajo una enseñanza teórica y práctica. 
La metodología CTIAM considera el desarrollo del pensamiento crítico, mediante el que se espera se propicie la resolución de retos, se empodere al estudiante como protagonista de su experiencia, a fin de que cuestione y reflexione sobre su proceso de aprendizaje para que llegue a sus propias conclusiones y logre construir sus conocimientos.

Al situarse dentro del constructivismo, se considera que CTIAM no presenta un método único; no obstante, se caracteriza por el empleo de pedagogías reconocidas como activas. De manera general, se identifica a CTIAM con el aprendizaje basado en proyectos, aunque se utilizan otras más como el aprendizaje basado en problemas, el uso de herramientas tecnológicas, la gamificación, entre otras.

Si bien el enfoque CTIAM en América Latina aún se encuentra en una etapa temprana de desarrollo, este ha cobrado fuerza a través de iniciativas particulares, nacionales, como el caso de Colombia, donde se plasma como una propuesta de mejora curricular; y, regionales, como la de Alianza Pacífico (a la que pertenecen México, Colombia, Perú y Chile).

En cuanto a la relación entre competencia lectora y CTIAM, destaca la reflexión de Baines (2015) sobre un modelo curricular idóneo para el futuro, donde señala que este solo se logrará cuando se extienda el uso del lenguaje a la innovación para así crear una alfabetización propia del siglo xxI, donde la lectura y la escritura se incorporen en el uso de la tecnología mediante la utilización de un pensamiento crítico. Lo anterior Baines lo considera necesario para la planeación didáctica de la competencia lectora, puesto que concibe habrá una demanda de lectores más sofisticados y eficaces en todo tipo de soportes.

Por su parte, Lewis (2015), en su investigación, retoma la propuesta de CTIAM y se enfoca en el valor de las humanidades mediante lo cual reconoce la importancia en el currículo educativo del pensamiento crítico y humanístico, habilidades analíticas, de metacognición, junto con las lectoras, en las que nombra la comprensión y el análisis textual.
La investigación del Institute for Entrepreneurschip in Education Caster Family Center for Nonprofit and Philanthropic Research (2017) describe hallazgos en cuanto a la relación de lectura con la educación CTIAM; los aciertos pueden resumirse en: la incorporación de materiales de alfabetización con investigación práctica, el uso de textos informativos y exposiciones múltiples de las palabras clave para el aprendizaje de vocabulario específico para el despliegue de actividades de lectura, escritura y habla.

Este informe admite que la lectura tiene una enorme influencia en el desarrollo de los estudiantes en la dimensión afectiva, conductual, cognitiva y metacognitiva del aprendizaje; a través de este reconocimiento es que se realizan actividades de lectura para llevar los temas de CTIAM. Entre ellas destacan:

- La lectura de textos con un contenido multidisciplinario para el desarrollo de habilidades de lectoescritura, conocimiento de vocabulario especializado junto con habilidades disciplinarias.

- El desarrollo de procesos intelectuales que comparte la lectura con los campos de la educación CTIAM: observar, clasificar, inferir, predecir y comunicar.

- El uso de textos informativos y su combinación con textos de otro género.

- El empleo de la lectura con experiencias prácticas.

- La instrucción de la lectura y la escritura a la par de otras disciplinas.

- La incentivación de la lectura fuera del aula bajo un propósito.

- Adquisición de lenguaje académico en áreas de contenido mediante la exposición múltiple de las palabras clave a través de la lectura, la escritura y la práctica oral.

- El ejercicio de la lectura digital.

- Se expone que los efectos positivos de estas actividades ocurren tanto en entornos formales como informales, siendo los segundos más propensos a motivar el gusto por la lectura y por temas CTIAM. 


\section{Metodología}

El objetivo principal del estudio fue proponer estrategias metodológicas para el desarrollo de la competencia lectora basadas en la educación CTIAM. El marco teórico que guio el estudio de la competencia lectora se ubica dentro del modelo educativo por competencias, el cual corresponde al enfoque constructivista; sin embargo, para efectos de esta investigación se situó concretamente en el socioconstructivismo -el cual otorga mayor importancia a los efectos socioculturales del aprendizaje, se centra en la generación colectiva del significado y del conocimiento compartido intersubjetivamente- debido a la postura que observan los autores contemporáneos que se retoman.

En virtud de esto, se estipuló un trabajo de enfoque cualitativo y de corte descriptivo. La recolección de datos se valió de la revisión de textos y documentos. En primera instancia, se delimitaron los elementos que conforman esta investigación mediante la búsqueda de fuentes en la que se utilizó el método deductivo, a través de una selección, organización, lectura y un análisis de información. Con respecto al tema de competencia lectora se revisaron 20 libros, 2 tesis de posgrado, 14 artículos en revistas especializadas y 4 páginas web (estas constituyen a los sitios oficiales de la SEP, ONU, PISA y OCDE). Sobre la educación CTIAM se revisaron 2 libros (en este tema se halló que existe un mayor número de publicaciones en revistas que en libros); 2 tesis de posgrado, 19 artículos en revistas especializadas y 4 páginas web (estas constituyen a los sitios de OCDE, Banco Mundial y del sitio de la autora Yakman). La delimitación temporal que dispuso su organización va del año 2000, año en el que surge la evaluación PISA y, posteriormente, la educación CTIAM (2006); hasta el año 2018, periodo en el que se ubican las publicaciones sobre competencia lectora y se emite la revisión conceptual por parte de PISA.

Para el análisis de la información se optó por utilizar un método de categorización y triangulación. Este último, como señalan Vallejo y Finol Franco (2009), ofrece al investigador diversas vías o distintos caminos para contrastar diferentes puntos de vista o fuentes de datos -además de teorías y métodos- en el estudio del fenómeno, en este caso, el de la competencia lectora.

En la construcción de categorías de análisis, estas se fueron depurando conceptualmente a partir del análisis de la información, para lo cual se valió del método de la triangulación. Fue así como se realizó una revisión, en primer lugar, teórica; y, posteriormente, metodológica, sobre las categorías emergentes que posibilitarían una propuesta para la elaboración de estrategias metodológicas para el desarrollo de dicha competencia.

De esta manera, se proponen cuatro elementos para la elaboración de estrategias, como resultado de la convergencia categorial entre la competencia lectora y la educación CTIAM; estos son: interdisciplinariedad, contextualización, actitud crítica y lectura digital.

Así se presenta, primeramente, el análisis teórico de los elementos a fin de señalar las modificaciones del contenido (definidas en el apartado 4.1) y, posteriormente, se señala la aplicación metodológica para la elaboración de tales estrategias mediante ejemplos descritos como acciones (apartado 4.2).

A continuación, la Tabla 1 presenta los conceptos y la definición de los elementos de la propuesta: 


\section{Tabla 1}

Propuesta para la elaboración de estrategias metodológicas para el desarrollo de la competencia lectora basadas en educación CTIAM

\begin{tabular}{|c|c|c|c|c|c|}
\hline Área & $\begin{array}{l}\text { Elementos para } \\
\text { el desarrollo de la } \\
\text { competencia lectora }\end{array}$ & Concepto & $\begin{array}{c}\text { Rol en intervención } \\
\text { docente } \\
\text { + rol en el aprendizaje } \\
\text { del estudiante }\end{array}$ & $\begin{array}{l}\text { Competencia } \\
\text { lectora }\end{array}$ & $\begin{array}{l}\text { Educación } \\
\text { CTIAM }\end{array}$ \\
\hline \multirow{3}{*}{ 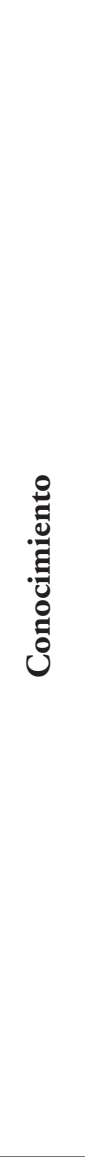 } & $\begin{array}{l}\text { Interdisciplinariedad } \\
\text { (teórico) }\end{array}$ & $\begin{array}{l}\text { Relación entre } \\
\text { disciplinas. } \\
\text { Aporte de } \\
\text { conocimientos } \\
\text { para interpretar un } \\
\text { fenómeno } \\
\text { (temas de estudio) } \\
\text { Rasgo: múltiple }\end{array}$ & $\begin{array}{l}\text { Contribuye a transferir } \\
\text { conocimientos entre } \\
\text { disciplinas }\end{array}$ & $\begin{array}{c}\text { Texto(s) } \\
\text { interdisciplina- } \\
\text { rio(s), } \\
\text { Tema "x" } \\
+ \\
\text { Claro contexto }\end{array}$ & $\begin{array}{l}\text { Transferencia de } \\
\text { conocimientos y } \\
\text { uso de distintas } \\
\text { competencias } \\
\text { para favorecer a } \\
\text { su ampliación y } \\
\text { profundidad. }\end{array}$ \\
\hline & $\begin{array}{l}\text { Contextualización } \\
\text { (aplicado) }\end{array}$ & $\begin{array}{l}\text { Relación entre tema/ } \\
\text { problema } \\
\text { con "situación real" } \\
\text { Rasgo: usabilidad }\end{array}$ & $\begin{array}{l}\text { Identificar, proponer } \\
\text { actividades de } \\
\text { aprendizaje que se } \\
\text { vinculan con entorno } \\
\text { escolar, comunitario, } \\
\text { laboral y social. } \\
\text { / } \\
\text { Resolución mediante el } \\
\text { despliegue de distintas } \\
\text { disciplinas }\end{array}$ & $\begin{array}{l}\text { Diversas situaciones } \\
\text { y usos de la lectura }\end{array}$ & $\begin{array}{c}\text { Aprendizaje que } \\
\text { combina la teoría } \\
\text { con la práctica. } \\
\text { Contexto general } \\
\text { y contexto } \\
\text { específico de un } \\
\text { campo. }\end{array}$ \\
\hline & $\begin{array}{l}\text { Lectura digital } \\
\text { (aplicado) }\end{array}$ & $\begin{array}{l}\text { La comprensión y } \\
\text { aprehensión de la } \\
\text { lectura mediante la } \\
\text { aplicación tecnológica. } \\
\text { Rasgo: usabilidad } \\
\text { tecnológica. }\end{array}$ & $\begin{array}{c}\text { Gestión de las TIC } \\
\text { como herramienta } \\
\text { en la enseñanza y } \\
\text { aprendizaje. } \\
\text { Comprensión y } \\
\text { aprehensión de las TIC. }\end{array}$ & $\begin{array}{l}\text { Lectura digital } \\
\text { Orienta, gestiona, } \\
\text { mediante el uso de } \\
\text { distintos códigos y } \\
\text { de múltiples canales } \\
\text { de producción. }\end{array}$ & $\begin{array}{c}\text { Incorporación } \\
\text { de contextos y } \\
\text { situaciones de la } \\
\text { vida cotidiana } \\
\text { mediante el uso } \\
\text { de la tecnología. }\end{array}$ \\
\hline 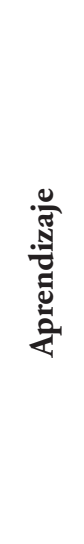 & $\begin{array}{l}\text { Actitud crítica } \\
\text { (aplicado) }\end{array}$ & $\begin{array}{c}\text { Relación entre } \\
\text { aprendizaje mental } \\
\text { y acción: actitud } \\
\text { de reflexión, } \\
\text { cuestionamiento } \\
\text { y construcción de } \\
\text { argumentos ante } \\
\text { la adquisición de } \\
\text { conocimientos como } \\
\text { en el propio proceso de } \\
\text { aprendizaje. } \\
\text { Rasgo: autonomía, } \\
\text { libertad. }\end{array}$ & $\begin{array}{l}\text { Gestiona, alimenta, } \\
\text { propone. } \\
\text { / } \\
\text { Argumentación, } \\
\text { razonamiento, } \\
\text { valoración y análisis. }\end{array}$ & $\begin{array}{l}\text { Lectura crítica. } \\
\text { Cuestiona, analiza, } \\
\text { reflexiona y } \\
\text { argumenta sobre } \\
\text { el aspecto literal e } \\
\text { implícito del texto. }\end{array}$ & $\begin{array}{c}\text { Reflexión sobre } \\
\text { las razones del } \\
\text { pensamiento y de } \\
\text { la acción. }\end{array}$ \\
\hline
\end{tabular}

Nota. Tomado de Pérez (2019). 
Como se observa en la Tabla 1, los elementos expuestos se identifican en dos áreas: la del conocimiento, que refiere el medio y las observaciones metódicas a través de las cuales se llevan a cabo los procesos mentales y que en este caso tiene que ver con aquello que contribuye para la construcción de significados; y otra, la del aprendizaje, donde se observa el ejercicio del conocimiento.

Asimismo, se hace una diferenciación entre tipo teórico y aplicado, lo cual se define por la acción que se ejerce. En este sentido, se observa que la interdisciplinaridad es la única de corte teórico, ya que involucra el entramado de distintos conocimientos.

Los cuatro elementos centrales se definen como:

- Interdisciplinariedad: de tipo teórico, su origen se ubica en la educación CTIAM; no obstante, para la competencia lectora se propone el empleo de textos interdisciplinarios, donde se aborde un tema central y se ubique un contexto. Este concepto contiene un rasgo múltiple por los elementos que lo conforman; por lo tanto, la actuación del docente habrá de procurar esta relación en la transferencia de conocimientos interdisciplinarios; mientras que el alumno habrá de aplicarlos junto con las competencias pertinentes.

- Contextualización: de tipo aplicado y con rasgo de usabilidad; surge al considerar la importancia del contexto en CTIAM y la competencia lectora. Señala la existencia de una relación entre el tema del texto con una situación real. Para su ejercicio será necesario el despliegue de diferentes competencias y, por ende, de los conocimientos de distintas disciplinas. El reto del profesor será identificar, crear y proponer actividades de aprendizaje donde se vincule el entorno escolar, ya sea con el comunitario, laboral o social.

- Actitud crítica: esta se conforma del pensamiento crítico y de la lectura crítica, siendo la primera una competencia de orden superior y la segunda un nivel profundo y experto de lectura. Se encuentra un cruce entre la parte teórica de la visión sociocultural de la lectura y la práctica de CTIAM, ante lo cual se define como una actitud de cuestionamiento y reflexión, al establecer una relación entre el aprendizaje y la acción. En este sentido, el alumno logrará analizar, construir inferencias y argumentar sobre lo explícito e implícito de un texto. Requiere un trabajo profundo por parte del alumno; tiene un rasgo de autonomía y libertad. Por su parte, el profesor gestiona, alimenta y propone situaciones didácticas lectoras que inciten a una actitud crítica y que contribuyan a la argumentación, el razonamiento, la valoración y el análisis.

- Lectura digital: surge de la vinculación de lectura y tecnología; por ende, posee un rasgo de usabilidad tecnológica y como característica la aplicación del conocimiento. En este sentido, es que se piensa en la creación de estrategias que involucren la lectura en dispositivos digitales, para lo cual el docente habrá de fungir como gestor de las TIC, al utilizarlas como herramientas de enseñanza y aprendizaje para el desarrollo de habilidades de búsqueda, selección y comprensión de la información. Mientras que el alumno habrá de ejercer tales habilidades mediante la aprehensión y el uso del hipertexto.

En la propuesta se suma y describe el papel del docente y del alumno en cada uno de los elementos, lo cual contribuye a identificar la manera en que se habrá de actuar para el mejor despliegue de la competencia lectora.

\section{Resultados}

Se realizó una propuesta en términos generales a partir de un contexto interdisciplinario, pensado desde el área de lenguaje y comunicación. A través de esta propuesta se reconoce que cada disciplina contiene un campo de conocimiento y lenguaje propios, lo cual requiere para su lectura una práctica cognitiva particular. 
Cabe señalar que, aunque en la elaboración de estrategias se pensó en no dirigirlo a un nivel educativo específico para poder así proporcionar estrategias metodológicas extensivas, las que se describen en esta propuesta se centran en la educación preuniversitaria. Asimismo, los tipos de texto que se utilizan para ejemplificar las actividades se ubican en nivel de primaria, secundaria y media superior.

No obstante, la dificultad de los textos y de las actividades habrán de considerarse acorde al nivel académico, por lo que es recomendable la aplicación de adecuaciones. Las que aquí se describen pretenden ser solo un ejemplo para la realización de acciones y contenidos generales.

De esta manera, se diseñó la aplicación metodológica para la elaboración de estrategias para el desarrollo de la competencia lectora, la cual muestra el desarrollo de la metodología, tanto de los elementos que la conforman como del proceso y la acción para su aplicación. Lo anterior se ilustra en la Figura 1.

\section{Figura 1}

Aplicación metodológica para la elaboración de estrategias para el desarrollo de la competencia lectora

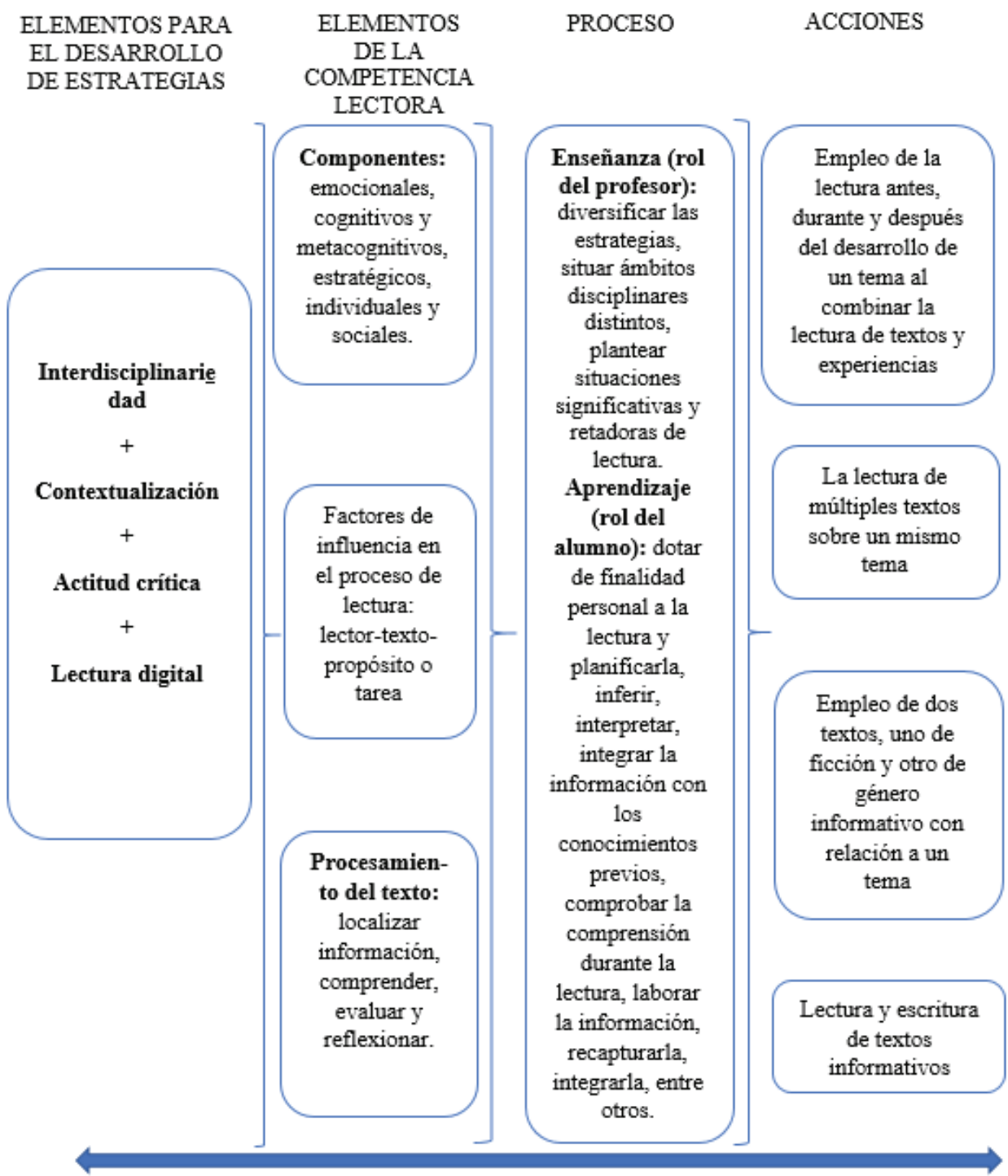

Nota. Tomado de Pérez (2019). 
Los cuatro elementos esenciales para la elaboración de estrategias que se proponen habrán de desplegarse con relación a los componentes, factores del proceso lector y procesamiento del texto, para lo cual se observa un rol de actuación por parte del profesor -como guía- y del alumno -como lector- para lo que finalmente se describen algunas actividades como acciones detonadoras.

En los siguientes rubros se presenta, primeramente, el análisis de la actitud crítica, los componentes de la competencia lectora, los factores de influencia, el procesamiento del texto y el proceso de enseñanza/aprendizaje, puesto que se considera necesario realizar algunas modificaciones como parte de la convergencia entre la educación CTIAM y la competencia lectora. Posteriormente, se describe la aplicación metodológica de la propuesta para el desarrollo de la competencia lectora.

\section{Análisis y modificaciones de los elementos para el desarrollo de la competencia lectora:}

\section{Actitud crítica}

Solé (2012) y Cassany (2005; 2008) señalan que para poder discernir entre los distintos usos de la lectura es necesario fomentar una actitud crítica; esto converge con el enfoque de CTIAM al hacer alusión al pensamiento crítico para la resolución de problemas. En esta propuesta se retoma únicamente este precepto como actitud, puesto que se reconoce que no existe paridad en el proceso cognitivo ni en el grado de complejidad.

\section{Componentes de la competencia lectora}

Los elementos que conciernen a este campo se conforman tanto por la visión dominante de la competencia lectora como por la visión sociocultural.

Los componentes cognitivos y metacognitivos se consideran parte del análisis lector, puesto que se reconoce como un proceso interactivo y transaccional, donde se toman en cuenta los elementos lingüísticos y los relativos a lo cognitivo, al identificar el conocimiento procedimental, puesto que el lector es quien habrá de regular y evaluar su proceder en el acto de lectura.

Se suman, también, los estratégicos, referentes a la conducta y autoevaluación como lector competente. Otro componente que se agrega es el emocional (OCDE, 2018; Solé, 2012); en esta propuesta se admite que al otorgar un propósito de lectura puede suscitarse una motivación y emoción en el lector, así mismo, aunque el propósito sea asignado, cuando el texto se pone en contexto y se descubre el sentido o uso es posible experimentar algún efecto emocional; esto tiene que ver con lo que Cassany $(2008 ; 2010)$ menciona al señalar que el aprendizaje de la lectura se logra solo cuando el lector se apropia del texto, le encuentra un sentido y lo dota de su propia historia.

En este sentido, se suma el logro individual y social; en la medida en que se llegue a ser un lector competente será posible formar parte y participar en una sociedad lectora. Esto es, cuando se descubren y utilizan los distintos usos de la lectura.

\section{Factores de influencia}

Se toman en cuenta las tres dimensiones que explican el proceso de lectura y que se conciben a partir de los aportes de Snow (2001) como: lector, actividad de lectura y propósitos de la tarea.

Con respecto al primero, en este trabajo se sitúa desde el punto de vista en el cual lector y texto se encuentran en un mismo nivel en el que mantienen una relación de interacción. A diferencia de Solé (2012), no se asume que las estrategias lectoras ya las posea el lector y solo sea necesario perfeccionarlas; por el contrario, se sostiene que es necesario desarrollarlas y fomentarlas.

Sobre la actividad de lectura, se considera es importante tomar en cuenta los elementos del texto en cuanto a su función, ya que de ellos dependerá su 
complejidad y tratamiento. Por texto se entiende todo aquello que conlleve a un acto de lectura; este podrá presentarse en distintos soportes y códigos; para efectos de esta investigación se centra en el código escrito; por soportes se refiere a libros, celulares, computadoras, periódicos, etc.

En lo que se refiere al propósito (o la tarea), se observa que este otorga de una finalidad al lector en su actuación frente al texto; de esta manera, existe una relación entre estos tres elementos, por lo cual se mantiene dentro de lo que constituye la competencia lectora.

\section{Procesamiento del texto}

En convergencia con lo que apunta PISA para el procesamiento del texto, se considera que localizar, comprender, evaluar y reflexionar dan cuenta de los diferentes tratamientos de la información, así como del comportamiento lector, los cuales poseen tratamientos cognitivos distintos.

Estos cuatro procesos se relacionan con los factores de influencia, puesto que es el lector quien identificará y dará el tratamiento al texto ante un determinado propósito, dentro de lo cual se ven inmiscuidos los componentes emocionales, cognitivos, etc. Asimismo, cada momento de la lectura puede contener uno de estos procesamientos, sea para responder una pregunta, cumplir con una tarea, o bien, por un ejercicio de conocimiento propio.

\section{Proceso enseñanza/aprendizaje}

En cuanto al rol del profesor y del estudiante se cree conveniente mantener los preceptos que dicta el socioconstructivismo en convergencia con la educación CTIAM, a través de lo cual la intervención del profesor, en estas estrategias, es como guía, observador, colaborador y co-alumno. En este sentido, Zanotto (2016) apunta que el profesor puede guiar al alumno al precisar sobre el tipo de análisis de textos que se espera se practique y bajo esta guía mejorar la competencia lectora. Asimismo, cada docente habrá de analizar y reflexionar sobre la finalidad de la estrategia que habrá de emplear, así como sobre las características de las disciplinas que se interrelacionen y sus prácticas lectoras.

Mientras tanto, el alumno mantiene un papel activo al otorgar de una finalidad personal a la lectura y mantener una interacción con el texto. En su tránsito de lector principiante a experto, habrá de desarrollar las habilidades necesarias para formarse como un lector competente, lo cual vincula directamente el rol del alumno con los componentes de la competencia lectora, los factores de influencia en el proceso de lectura y el procesamiento del texto.

\section{Acciones para el desarrollo de estrategias}

Las acciones son parte del cierre de la propuesta mediante las cuales se logra plasmar el contenido conceptual y del proceso, a través de la ejecución de actividades. Su diseño corresponde a la conjunción de la Tabla 1 y la Ilustración 1 al señalar todos los elementos para poner en acción las estrategias, mediante los rubros de: campos disciplinarios, propósito/tarea, actividades, habilidades lectoras, elementos y evidencias de aprendizaje. Esto se ejemplifica en los siguientes puntos:

\section{Empleo de la lectura antes, durante y después del desarrollo de un tema al combinar la lectura de textos y experiencias prácticas}

Los tres momentos de lectura de esta acción contienen una secuencia con un enfoque de aprendizaje basado en proyectos, a través del cual se vincula una actividad teórica con una práctica; esto último se relaciona directamente con el elemento de contextualización que se muestra en la Tabla 2: 
Tabla 2

Empleo de la lectura antes, durante y después del desarrollo de un tema

\begin{tabular}{|c|c|c|c|c|c|}
\hline Tema & & $\mathrm{Huc}$ & rtos urbanos & & \\
\hline $\begin{array}{c}\text { Campos } \\
\text { disciplinarios: }\end{array}$ & & espańol, ciencia, tecno & logía, ingenierí & y matemáticas. & \\
\hline Momento & $\begin{array}{l}\text { Propósito/ } \\
\text { tarea }\end{array}$ & Actividades & $\begin{array}{l}\text { Habilidad(es) } \\
\text { lectora(s) }\end{array}$ & Elementos & $\begin{array}{c}\text { Evidencias } \\
\text { de } \\
\text { aprendizaje }\end{array}$ \\
\hline $\begin{array}{l}\text { Antes } \\
\text { (lectura } \\
\text { previa) }\end{array}$ & $\begin{array}{l}\text { Exploración } \\
\text { del tema, } \\
\text { introducción } \\
\text { de conceptos }\end{array}$ & $\begin{array}{l}\text { 1. Formulario hidroponía } \\
\text { 2. Lectura de textos sobre } \\
\text { cultivos en el espacio: } \\
\text { http://hidroponia. } \\
\text { mx/nasa-cultivos- } \\
\text { hidroponicos-en-el- } \\
\text { espacio/ }\end{array}$ & $\begin{array}{l}\text { Localiza } \\
\text { información }\end{array}$ & $\begin{array}{c}\text { Interdisciplinariedad, } \\
\text { lectura digital }\end{array}$ & $\begin{array}{c}\text { Ideas } \\
\text { principales }\end{array}$ \\
\hline $\begin{array}{l}\text { Durante } \\
\text { (lectura } \\
\text { central) }\end{array}$ & $\begin{array}{l}\text { Lectura crítica, } \\
\text { localización y } \\
\text { definición de } \\
\text { conceptos }\end{array}$ & $\begin{array}{l}\text { 3. Lectura sobre la } \\
\text { elaboración de huerto } \\
\text { hidropónico. } \\
\text { Texto: } \\
\text { Manual de hidroponía, } \\
\text { Margarita Araceli } \\
\text { Zárate Aquino, 2014, } \\
\text { UNAM } \\
\text { 4. Preguntas de reflexión } \\
\text { sobre la elaboración } \\
\text { de la práctica y los } \\
\text { resultados. } \\
\text { Elaboración de un } \\
\text { informe sobre la } \\
\text { descripción del proceso, } \\
\text { los resultados y las } \\
\text { conclusiones. }\end{array}$ & $\begin{array}{l}\text { Comprende, } \\
\text { evalúa y } \\
\text { reflexiona. }\end{array}$ & $\begin{array}{l}\text { Interdisciplinariedad, } \\
\text { contextualización, } \\
\text { actitud crítica }\end{array}$ & Informe \\
\hline
\end{tabular}

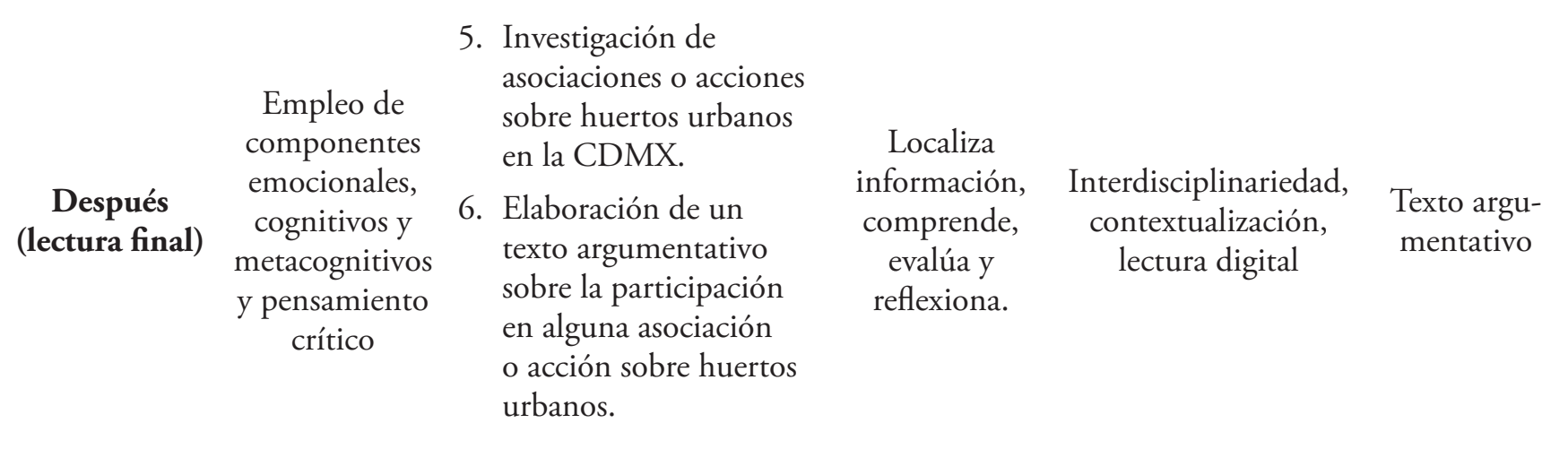

Nota. Tomado de Pérez (2019). 
El ejemplo anterior muestra una corresponsabilidad de los momentos de lectura con el propósito de tarea, actividades, habilidades lectoras, categorías de análisis y evidencias de aprendizaje.

Con relación al propósito descrito, se designa uno por cada tarea: inicia con la exploración del tema e introducción de conceptos; durante la lectura central se asigna la localización y definición de conceptos y una lectura crítica. En la tercera fase se realiza una actividad cierre que sirve de seguimiento; el propósito es el empleo de componentes emocionales cognitivos y metacognitivos a la par del pensamiento crítico, eso sucede una vez que el alumno ya se familiarizó con el tema para establecer y mantener una postura.

Las habilidades lectoras se presentan en secuencia con la lectura previa al recuperar lo esencial del texto; posteriormente se hace uso de la comprensión al integrar y generar inferencias, y al evaluar y comprender para llevar a cabo la práctica; en la última actividad se conjuntan las habilidades del procesamiento del texto.

Finalmente, se señalan los elementos centrales de la estrategia; estos no contienen un orden ni una jerarquía, sino que dependen de la actividad a realizar; por ejemplo, la interdisciplinariedad está presente en los tres momentos porque en el tema convergen las disciplinas que conforman CTIAM; en el momento previo y final se utilizan lecturas digitales, y en la lectura central y final se halla la contextualización.

Como se observa, la actividad de investigación incita al lector a tomar una postura después de buscar, analizar y reflexionar sobre el tema. En este sentido, las evidencias de aprendizaje están pensadas en una dificultad gradual, en atención a las actividades y habilidades lectoras.

\section{Empleo de dos textos: uno de ficción y uno de género informativo a través de un tema}

Esta acción compete al empleo de dos textos: uno literario y otro de tipo informativo; en este caso se trata de un cuento de Jorge Luis Borges titulado Funes el memorioso, que relata la historia de un hombre que lo recuerda todo y cómo repercute esto en su vida; $y$, por otro lado, se recurre a un texto informativo que describe las partes y funciones del sistema nervioso; entre estas últimas se halla la memoria. El tema que une a ambas lecturas se encuentra dentro del área de las ciencias, relativo a la memoria; como se expone en la Tabla 3:

\section{Tabla 3}

Empleo de dos textos: uno de ficción y uno de género informativo a través de un tema

\begin{tabular}{|c|c|c|c|c|}
\hline Tema: & \multicolumn{4}{|c|}{ La memoria } \\
\hline $\begin{array}{c}\text { Campos } \\
\text { disciplinarios: }\end{array}$ & \multicolumn{4}{|c|}{ español, ciencias, tecnología } \\
\hline Propósito/tarea & Actividades & $\begin{array}{c}\text { Habilidad(es) } \\
\text { lectora(s) }\end{array}$ & Elementos & $\begin{array}{c}\text { Evidencia de } \\
\text { aprendizaje }\end{array}$ \\
\hline $\begin{array}{l}\text { Conocimiento } \\
\text { del tema y los } \\
\text { elementos que lo } \\
\text { caracterizan }\end{array}$ & $\begin{array}{l}\text { 1. Texto ficción: Funes } \\
\text { el memorioso, de Jorge } \\
\text { Luis Borges. } \\
\text {-Localizar ideas centrales } \\
\text { ¿Qué es lo que se sabe } \\
\text { sobre la memoria? } \\
\text { ¿Qué es lo que se dice } \\
\text { sobre la memoria? }\end{array}$ & $\begin{array}{l}\text { Comprende, } \\
\text { evalúa y } \\
\text { reflexiona }\end{array}$ & $\begin{array}{c}\text { Interdisciplinariedad, } \\
\text { contextualización }\end{array}$ & $\begin{array}{l}\text { Reflexión } \\
\text { crítica por } \\
\text { escrito }\end{array}$ \\
\hline
\end{tabular}




\begin{tabular}{|c|c|c|c|c|}
\hline Propósito/tarea & Actividades & $\begin{array}{c}\text { Habilidad(es) } \\
\text { lectora(s) }\end{array}$ & Elementos & $\begin{array}{c}\text { Evidencia de } \\
\text { aprendizaje }\end{array}$ \\
\hline $\begin{array}{l}\text { Lectura crítica } \\
\text { para una } \\
\text { comprensión } \\
\text { profunda }\end{array}$ & $\begin{array}{l}\text { 2. Texto informativo: } \\
\text { lectura y discusión } \\
\text { grupal sobre el } \\
\text { sistema nervioso } \\
\text { central. } \\
\text {-Localizar ideas } \\
\text { centrales } \\
\text { ¿Qué es lo que se sabe } \\
\text { sobre la memoria? } \\
\text { 3. ¿Qué es lo que se dice } \\
\text { sobre la memoria? }\end{array}$ & $\begin{array}{l}\text { Localiza } \\
\text { información: } \\
\text { identifica ideas } \\
\text { principales. }\end{array}$ & $\begin{array}{l}\text { Interdisciplinariedad, } \\
\text { contextualización, } \\
\text { actitud crítica }\end{array}$ & $\begin{array}{l}\text { Reflexión } \\
\text { crítica por } \\
\text { escrito }\end{array}$ \\
\hline $\begin{array}{l}\text { Comparación } \\
\text { de ambos } \\
\text { textos, lectura } \\
\text { crítica para una } \\
\text { comprensión } \\
\text { profunda. }\end{array}$ & $\begin{array}{l}\text { 4. } \begin{array}{l}\text { Identificar y } \\
\text { señalar diferencias } \\
\text { estructurales de textos } \\
\text { (comparativo) }\end{array} \\
\text { 5. Analizar y comparar } \\
\text { los argumentos de los } \\
\text { dos textos. }\end{array}$ & $\begin{array}{l}\text { Localiza } \\
\text { información, } \\
\text { comprende, } \\
\text { evalúa y } \\
\text { reflexiona. }\end{array}$ & $\begin{array}{l}\text { Interdisciplinariedad, } \\
\text { contextualización, } \\
\text { actitud crítica, lectura } \\
\text { digital }\end{array}$ & Infografía \\
\hline
\end{tabular}

Nota. Tomado de Pérez (2019).

Como se aprecia en la Tabla 3, la actividad de inicio corresponde a abordar el tema central desde la mirada literaria. Aunque en este ejercicio se sugiere previamente un título, existe la opción de que sea el estudiante quien elija el trabajo de este género en correspondencia al caso de estudio. Esta acción muestra, además, el tratamiento de un tema de ciencias en conjunto con el aprendizaje en la materia de español, con relación a los textos informativos y literarios, lo cual hace presente el elemento de interdisciplinariedad.

Como actividad dos se realiza la lectura del tipo informativo -correspondiente al sistema nerviosocon el fin de localizar los elementos centrales.

En ambas actividades, además de identificar los elementos que caracterizan los géneros, se plantean algunas preguntas que contribuyen a comprender y evaluar el tema; estas también se utilizan para ambos textos a fin de situar una misma ruta de lectura. Al finalizar las lecturas se añade una reflexión comparativa de estructuras.
Con respecto a las habilidades, existe una jerarquía en el proceso lector al localizar información, comprender, evaluar y reflexionar, por lo cual cada una de estas corresponde a cada actividad. El momento medular se encuentra en la lectura de los dos géneros; al concernir un tema la lectura literaria requiere también de una observación crítica para comprender el tópico, en este caso, la memoria, así como para poder reconocer los aportes de cada género.

Como evidencias de aprendizaje se incita a la reflexión crítica de la lectura de ambos géneros que otorgue como resultado una infografía.

\footnotetext{
La lectura de múltiples textos sobre un mismo tema

Esta estrategia se diseña a partir del uso y de la comprensión de múltiples textos sobre un mismo tema. Si bien la enseñanza de la lectura a partir de un único texto es algo cotidiano en la práctica escolar,
} 
particularmente en la educación básica, en el nivel superior resulta ser una actividad común "leer distintos textos que informen desde distintas perspectivas sobre un mismo tema" (Sarmiento et al., 2009, p. 1).

Se funda en la perspectiva teórica de la comprensión del texto y el discurso denominada alfabetización de múltiples documentos complejos, la cual tiene como finalidad la construcción de significados a partir de distintos soportes textuales (Vega et al., 2013).

De esta manera, esta acción hace alusión directamente al elemento de interdisciplinariedad, a través de la cual existe una relación y un aporte de conocimientos entre disciplinas para interpretar un tema de estudio (véase Tabla 4).

\section{Tabla 4}

La lectura de múltiples textos sobre un mismo tema

\begin{tabular}{|c|c|c|c|c|}
\hline Tema: & \multicolumn{4}{|c|}{ Problemas de salud en niños con sobrepeso } \\
\hline $\begin{array}{c}\text { Campos } \\
\text { disciplinarios: }\end{array}$ & \multicolumn{4}{|c|}{ español, ciencia, tecnología y matemáticas. } \\
\hline Propósito/tarea & Actividades & $\begin{array}{c}\text { Habilidad(es) } \\
\text { lectora(s) }\end{array}$ & Elementos & $\begin{array}{l}\text { Evidencias de } \\
\text { aprendizaje }\end{array}$ \\
\hline
\end{tabular}

1. Consultar dos referencias básicas (capítulos de libros) y como mínimo tres referencias adicionales (artículos de investigación en revistas científicas, páginas web, informes oficiales).

diferentes fuentes de información Identificar y explicar ideas principales y conceptos clave. Analizar evidencias. Opinión argumentada
2. Responder a lo siguiente:

a. ¿ ¿cómo se define el sobrepeso infantil desde los sectores de salud pública? ¿quiénes son más propensos a presentarlo de acuerdo con algunos organismos internacionales?

a. ¿cuáles son las acciones que se han implementado a nivel nacional en las escuelas?

b. ¿Cómo difiere la perspectiva nacional con la internacional?

c. ¿Qué piensas de las medidas nacionales que hasta ahora se han tomado sobre esta situación?

$\begin{array}{ccc} & \begin{array}{c}\text { Interdisci- } \\ \text { plinariedad, }\end{array} & \begin{array}{c}\text { Elaborar una } \\ \text { Localiza }\end{array} \\ \text { contextua- } & \text { presentación } \\ \text { información, } & \text { lización, } & \text { multimedia } \\ \text { comprende, } & \text { lectura } & \text { como } \\ \text { evalúa y } & \text { digital, } & \text { resultado de la } \\ \text { reflexiona. } & \text { actitud } & \text { investigación. } \\ & \text { crítica. }\end{array}$

Interdisci-

Nota. Tomado de Pérez (2019). 
Esta acción se diseña a partir de la resolución de una tarea; de esta manera la evidencia de aprendizaje se indica desde la parte inicial. Es así como las actividades constituyen un proceso que habrá de culminar con el producto final, en este caso, la presentación multimedia. En dicho proceso se propicia establecer relaciones entre los diversos textos a través de su identificación, clasificación y comprensión, lo cual se señala dentro de la columna de actividades.

De tal forma que las habilidades lectoras estarán delineadas por las actividades, así como por los propósitos, con lo cual, después de localizar recursos de información, se identifican y explican ideas clave y conceptos, para después, mediante la relación de los textos, analizar evidencias e información en conflicto y emitir una argumentación fundamentada.

\section{Lectura y escritura de textos informativos}

Esta acción observa como objeto principal los textos informativos mediante el empleo de recursos multimedia en la búsqueda de información y exposición de una postura crítica sobre un tema, en este caso, sobre la alimentación vegetariana. Es necesario señalar que el tema -como en los casos anteriores- busca ser relevante, cercano a lo cotidiano, de tal manera que las habilidades desarrolladas se vinculen con la vida diaria, todo lo cual se enmarca en la Tabla 5:

\section{Tabla 5}

Lectura y escritura de textos informativos

\begin{tabular}{|c|c|c|c|c|}
\hline Tema: & \multicolumn{4}{|c|}{ La alimentación vegetariana } \\
\hline $\begin{array}{l}\text { Campos discipli- } \\
\text { narios: }\end{array}$ & \multicolumn{4}{|c|}{ español, ciencia, tecnología y matemáticas. } \\
\hline Propósito/tarea & Actividades & $\begin{array}{c}\text { Habilidad(es) } \\
\text { lectora(s) }\end{array}$ & Elementos & $\begin{array}{c}\text { Evidencias de } \\
\text { aprendizaje }\end{array}$ \\
\hline $\begin{array}{l}\text { Conocimiento } \\
\text { del tema y de los } \\
\text { elementos que lo } \\
\text { caracterizan }\end{array}$ & $\begin{array}{l}\text { 1. Lectura sobre los tipos } \\
\text { de alimentación. } \\
\text { 2. Investigación indi- } \\
\text { vidual sobre el vegetar- } \\
\text { ianismo y sus variantes } \\
\text { en repositorios insti- } \\
\text { tucionales. }\end{array}$ & $\begin{array}{l}\text { Localiza infor- } \\
\text { mación. }\end{array}$ & $\begin{array}{l}\text { Interdisciplinariedad, } \\
\text { contextualización }\end{array}$ & $\begin{array}{c}\text { Identificar ideas } \\
\text { principales } \\
\text { (comparativo) y } \\
\text { presentarlo. }\end{array}$ \\
\hline $\begin{array}{l}\text { Empleo de compo- } \\
\text { nentes emocionales, } \\
\text { cognitivos y meta- } \\
\text { cognitivos y pens- } \\
\text { amiento crítico }\end{array}$ & $\begin{array}{l}\text { 3. Desarrollo de un } \\
\text { punto de vista artic- } \\
\text { ular (defensa o crítica) } \\
\text { sobre un tipo de dieta. } \\
\text { Trabajo en equipo. }\end{array}$ & $\begin{array}{l}\text { Comprende, } \\
\text { evalúa y reflex- } \\
\text { iona. }\end{array}$ & $\begin{array}{l}\text { Interdisciplinariedad, } \\
\text { contextualización, } \\
\text { actitud crítica }\end{array}$ & $\begin{array}{l}\text { Postura crítica, } \\
\text { argumento. }\end{array}$ \\
\hline $\begin{array}{c}\text { Empleo del texto } \\
\text { como fuente de } \\
\text { información y } \\
\text { expresión de ideas } \\
\text { nuevas }\end{array}$ & $\begin{array}{l}\text { 4. Creación de una } \\
\text { narración digital (se } \\
\text { utilizan imágenes, } \\
\text { gráficas y texto) } \\
\text { Trabajo en equipo. }\end{array}$ & $\begin{array}{l}\text { Localiza infor- } \\
\text { mación, } \\
\text { comprende, } \\
\text { evalúa y reflex- } \\
\text { iona. }\end{array}$ & $\begin{array}{l}\text { Interdisciplinariedad, } \\
\text { contextualización, } \\
\text { actitud crítica }\end{array}$ & $\begin{array}{l}\text { Construcción } \\
\text { de narraciones } \\
\text { y expresión de } \\
\text { opinión crítica. }\end{array}$ \\
\hline $\begin{array}{l}\text { Argumentación } \\
\text { fundamentada }\end{array}$ & $\begin{array}{l}\text { 5. Publicación y discusión } \\
\text { de narración digital y } \\
\text { discusión en línea. }\end{array}$ & $\begin{array}{l}\text { Evalúa y reflex- } \\
\text { iona. }\end{array}$ & Actitud crítica & $\begin{array}{l}\text { Postura crítica, } \\
\text { argumento. }\end{array}$ \\
\hline
\end{tabular}

Nota. Tomado de Pérez (2019). 
Esta acción contiene tanto actividades dirigidas por el docente, como trabajo individual y colaborativo por parte del alumnado. El cierre estará dado por la creación de una narración digital; esto contribuirá a que el alumno ejercite la lectura mediante distintas presentaciones como la imagen y la gráfica, acompañadas de un texto escrito.

Para todas las acciones anteriores se recomienda que el docente realice a la par de los alumnos las habilidades contenidas en la competencia lectora para que de esta manera pueda compartir el trabajo como guía y como lector competente.

Cabe señalar que, aunque se admite que el desarrollo de actividades en el contexto escolar y en el cotidiano contribuyen a una mejor formación de lectores competentes, este trabajo se limita al ámbito académico debido al tiempo, a la extensión y al objetivo establecido.

\section{Conclusiones}

Como respuesta a la pregunta de investigación, al indagar sobre los elementos teórico-metodológicos que se necesitan para poder elaborar estrategias que contribuyan al desarrollo de la competencia lectora basados en la educación CTIAM, a fin de lograr una alfabetización funcional, se concluye que la educación CTIAM y la competencia lectora pueden converger a través de la interdisciplinariedad, contextualización, actitud crítica y lectura digital. A través de la interdisciplinariedad se busca ir más allá de la enseñanza de la lectura dentro de la materia de Español y procurar el desarrollo de la competencia lectora como un compromiso de toda disciplina.

Mediante la contextualización se destaca la importancia de situar actividades en contextos reales para exponer su aplicación y uso en el mundo real. Al colocar la lectura digital como elemento central se busca reconocer a esta como práctica y no como herramienta. En cuanto a la actitud crítica, se busca que un lector crítico tienda hacia una alfabetización funcional al lograr relacionar la lectura con otras prácticas y, por tanto, con otras disciplinas mediante la comprensión y apropiación de los textos a través de su uso y de la adopción de una actitud o postura ante estos.

Si bien la educación CTIAM no se originó para emplearse dentro del área de la lectura, esta tiene un lugar desde las artes del lenguaje gracias a la aportación de Yakman a esta propuesta educativa (Yakman y Lee, 2012).

Asimismo, el informe del Instituto de Emprendimiento en Educación de la Universidad de San Diego (2017) certifica resultados positivos en cuanto a la vinculación entre lectura y educación CTIAM en el despliegue de estrategias; entre estas destacan el empleo de textos con un contenido multidisciplinario para el desarrollo de habilidades de lectoescritura y a la vez cultivar habilidades disciplinarias, el uso de textos informativos y su combinación con textos de otro género, el empleo de la lectura con experiencias prácticas, la adquisición de vocabulario especializado y el ejercicio de la lectura digital.

El objetivo planteado se logró llevar a cabo al elaborar una propuesta en donde se toma en cuenta el papel del profesor como guía y del alumno como lector; se describen actividades de aprendizaje para las que se determina un propósito; se distinguen habilidades lectoras y se establecen evidencias de aprendizaje, a partir de un tema en donde confluyen distintos campos disciplinarios. Todo esto con relación a los cuatro elementos de convergencia.

Las acciones ofrecidas intentan exponer la pertinencia del desarrollo de la competencia lectora en todas las áreas académicas mediante un aprendizaje interdisciplinario en aras de una alfabetización funcional a fin de lograr un aprendizaje permanente. Para esto, las acciones se describen en términos de actividades, las cuales podrán realizarse durante y después de clase; para cada disciplina se podrá trabajar con contenidos y/o conceptos; existe un interés en la comprensión y no solo en el producto; y se mantiene la idea de una lectura epistémica.

Se juzga que, mediante los elementos propuestos, será posible establecer un propósito de lectura, sea para una actividad académica o un uso particular; al mismo tiempo se habrá de ejercitar una lectura crítica al indagar, seleccionar, comprender y explicar aquello 
que se lee dentro de un ámbito interdisciplinario, todo lo cual lo llevará a una mejor competencia como lector en contextos reales.

Relativo a su implementación, González (2018) observa que los proyectos que se basan en la educación CTIAM no están organizados por sesiones semanales. Si bien se reconoce esta dificultad en la planeación de la educación CTIAM, desde este trabajo se considera que es necesario recalcar el papel que juega el docente puesto que él es guía en la implementación de estas estrategias. Por tanto, en esta propuesta no se específica el tiempo para cada actividad puesto que cada profesor habrá de establecer el tiempo destinado de acuerdo con las horas y los temas de la asignatura.

Por otro lado, en la revisión de la literatura expuesta se encontró que la competencia lectora es un concepto que puede redefinirse desde una visión amplia sobre la lectura en respuesta a las formas de ser lector del siglo XxI. Ante lo que se concluye que dicha competencia es un aprendizaje fundamental, de adquisición y dominio permanente (Solé, 2012) en cualquier nivel educativo.

Con relación a las visiones contemporáneas sobre la lectura, situadas desde la perspectiva sociocultural, fue posible hallar un punto de convergencia en su concepción como una actividad compleja, dinámica y social, que otorga gran importancia a la lectura digital como una práctica lectora vigente.

Se define a la competencia lectora como un aprendizaje multidimensional (Solé, 2012) y complejo (Solé, 2012; Cassany, 2008), que requiere de capacidades cognitivas, metacognitivas, afectivas e individuales (PISA, 2018) y que habrá de ejercerse socialmente, para lo cual requiere una mayor atención en las capacidades de esta índole. De esta manera, se piensa en la necesidad de establecer una visión integradora a través de la cual se diversifiquen estrategias y se sitúen diferentes ámbitos disciplinares en su didáctica, para así lograr formar lectores críticos y competentes.

Esta propuesta intenta no solo ser una aportación para el contexto educativo mexicano, sino para el campo de la didáctica, al presentar un andamiaje de estrategias metodológicas para su posible aplicación como una alternativa para la formación de lectores competentes.
Finalmente, futuras investigaciones podrían centrarse en la aplicación de las estrategias metodológicas propuestas, específicamente en un grado, a fin de observar sus alcances, resultados y limitaciones. Asimismo, sería de gran utilidad ampliar la serie de acciones, puesto que estas se presentan a manera de ejemplo.

\section{Referencias}

Ángulo, N. (2017). Glosario de la docencia en la sociedad del conocimiento. IPN-Práctica educativa.

Baines, L. (2015). Emerging Technologies for STAM Education. Full STEAM AHEAD. Educational Communications and Technology: Issues innovations. Springer International Publishing Suiza. 246-258. https://doi.org/10.1007 / 978-3-31902573-5_13

Bañales, G.; Vega, N.; Reyna, A. y Rodríguez, S. (2013). Investigación de la lectura y la

escritura académica en la educación media y superior en México: perspectivas, avances y desafios, en Lenguaje y educación. Temas de investigación educativa en México. Fundación SM-Consejo Puebla de Lectura, A.C.

Cassany, D. (2005). Los significados de la comprensión crítica. Lectura y Vida, 26(3), 32-45. http:// www.lecturayvida.fahce.unlp.edu.ar/numeros/ a26n3/26_03_Cassany.pdf

Cassany, D. (2006). Tras las lineas. Sobre la lectura contemporánea. Anagrama.

Cassany, D. (2008). Prácticas letradas contemporáneas. https://repositori.upf.edu/bitstream/handle/ 10230/21294/Cassany_LEERES.pdf

Cassany, D. (2010). Aproximación a la literacidad critica, 2(28), 353-374. https://doi.org/10.5007/2175795X.2010v28n2p353

Cassany, D. (2012). En_linea. Leer y escribir en la red. Anagrama.

Cordón, J.A. y Jarvio, A. O. (2015) ¿Se está transformando la lectura y la escritura en la era digital? Revista Interamericana de Bibliotecologia, 38(2), 137. https://doi: 10.17533/udea. rib.v38n2a405 
García, Y., Reyes, D. y Zamorano, T. (2018). Educación para el sujeto del siglo XXI: principales características del enfoque STEAM desde la mirada educacional. Contextos: Estudios de Humanidades y Ciencias Sociales, (41). http://revistas.umce.cl/ index.php/contextos/article/view/1395/1428

González, A. M. (2018, 28 de agosto) STEM/CTIM: Pros y contras o sólo contras [blog]. Formación IB. http://formacionib.org/noticias/?STEMCTIM-Pros-y-contras-o-solo-contras

INEE. (2017). PLANEA. Resultados Nacionales 2017. http://www.inee.edu.mx/index.php/resultados-nacionales-2017.

INEGI. (2018, 27 de abril). Reporte sobre el módulo de lectura (MOLEC) [Comunicado de prensa núm. 166/18]. http://www.beta.inegi.org.mx/ contenidos/saladeprensa/boletines/2018/EstSociodemo/MOLEC2018_04.pdf

Institute for Entrepreneurship in Education Caster Family Center for Nonprofit and Philanthropic. Research. (2017). The Role of Books and Reading in STEM: An Overview of the Benefits for Children and the Opportunities to Enhance the Field. Universidad de San Diego-Foundation The Molina. http://43ot971vwwe7okplr1iw2ql1-wpengine. netdna-ssl.com/wp-content/uploads/2018/02/ STEM-Literacy_VP-November-2017-Final. V3.pdf

Katz-Buonincontro, J. (2018). Gathering STE(A)M: Policy, curricular, and programmatic developments in arts-based science, technology, engineering, and mathematics education Introduction to the special issue of Arts Education Policy Review: STEAM Focus. Arts Education Policy Review, 119(2), 73-76, https://doi.org/10.1080/106329 13.2017.1407979

Lewis, A. (2015). Emerging Technologies for STAM Education. Full STEAM AHEAD. Educational Communications and Technology: Issues innovations. Springer International Publishing Suiza. 259-276. https://doi.org/10.1007 / 978-3-31902573-5_13

Liao, C. (2016). From Interdisciplinary to Transdisciplinary: An Arts-Integrated Approach to
STEAMEducation.ArtEducation,69(6),44-49, https://doi.org/10.1080/00043125.2016. 1224873

Makuc, M. (2011). Teorías implícitas sobre comprensión textual y la competencia lectora de estudiantes de primer año de la Universidad de Magallanes. Estudios Pedagógicos, 37(1), 237-254. https://dx.doi.org/10.4067/S0718-07 052011000100013

Moreno, M. (2008). Alfabetización digital: el pleno dominio del lápiz y el ratón. Comunicar, 30, 137-146. https://doi.org/10.3916/c30-200802-007

OCDE. (2015) Resultados PISA 2015 México. https:// www.oecd.org/pisa/PISA-2015-MexicoESP.pdf

OCDE. (2018). Marco teórico de lectura. Pisa 2018. https://www.mecd.gob.es/inee/dam/jcr:2f1081a1-c1e4-4799-8a49-9bc589724ca4/ marco\%20teorico\%20lectura\%202018_esp_ ESP.pdf

Pérez, J. (2015). STEM, STEAM... ¿pero eso qué es? Didactalia. http://odite.ciberespiral.org/ comunidad/ODITE/recurso/stem-steam-pero-eso-que-es/58713dbd-414c-40eb-96435 dee $56 f 191 \mathrm{~d} 3$

Pérez, M. E. M. (2019). Propuesta de estrategias metodológicas para el desarrollo de la competencia lectora, basadas en educación Ciencia, Tecnología, Ingeniería, Artes y Matemáticas (CTIAM) [tesis de maestría, Instituto Politécnico Nacional]. Repositorio Institucional http://tesis.ipn.mx/ handle/123456789/27431

Reimers, F. (2006). Lectores competentes y expansión escolar en México. Continuidad intergeneracional y desafíos de política educativa. En Goldin, D. (coordinador), Encuesta Nacional de Lectura. Informes y evaluaciones (pp. 173-202). CONACULTA.

Riascos, J. y Valverde O. (2018). Lectura Crítica: realidades y contribuciones pedagógicas y didácticas. Excelsium Scientia: Revista Internacional de Investigación, 2(1), 79-92, https://doi.org/10.31948/ RevExcelsium/2-1.art6 
Rodríguez, J. (2004). Las alfabetizaciones digitales. Revista Bordón. 56, 1-20.

Ruiz, V. (2017). Diseño de proyectos STEAM a partir del curriculum actual de Educación Primaria utilizando Aprendizaje Basado en Problemas, Aprendizaje Cooperativo, Flipped Classroom y Robótica Educativa [Tesis doctoral, Universidad CEU Cardenal Herrera].

Sarmiento, A. S., Carrasco, A. C. y Tello, P. (2009). Lectura de múltiples textos. Explicar la comprensión integrada de textos desde la epistemología personal. X Congreso Nacional de Investigación Educativa. 1-11. http://www.comie.org.mx/ congreso/memoriaelectronica/v10/pdf/area_ tematica_01/ponencias/0885-F.pdf

SEP. (2011a). Manual de procedimientos para el fomento y la valoración de la competencia lectora en el aula. SEP.

SEP. (2011b). Plan de estudios 2011. Educación Básica. SEP.

SEP. (2013). Propuesta para la renovación de la sección "Competencia lectora" en el reporte de evaluación. SEP.

SEP. (2017) Modelo Educativo para la Educación Obligatoria. SEP. https://www.gob.mx/cms/uploads/ attachment/file/198738/Modelo_Educativo_ para_la_Educacio_n_Obligatoria.pdf

Snow, C.E. (2001). Reading for understanding. Santa Mónica, CA: RAND Education the Science and Technology Police Institute. https:/www. rand.org/content/dam/rand/pubs/monograph_reports/2005/MR1465.pdf

Solé. I. (2012). Competencia lectora y aprendizaje. Monográfico. Revista Iberoamericana de Educación. 59, 43-61. https://rieoei.org/historico/ documentos/rie59a02.pdf
Trillos-Pacheco, J. J. (2013). La lectura hipermedial y su incidencia en la comprensión lectora en estudiantes universitarios. Palabra Clave, 16(3), 944-992. http://palabraclave.unisabana.edu.co/ index.php/palabraclave/article/view/2664/3322

Vallejo, R. y Finol de Franco, M. (2009). La triangulación como procedimiento de análisis para investigaciones educativas. Revista electrónica de humanidades, educación y comunicación social. 7 , 117-133 https://dialnet.unirioja.es/servlet/articulo? codigo $=3063110$

Vega, N. A., Bañales, G. y Reyna, A. (2013). La comprensión de múltiples documentos en la universidad: el reto de formar lectores competentes. Revista mexicana de investigación educativa, 18(57), 461-481. http://www.scielo.org.mx/scielo.php?script=sci_ arttext\&pid=S1405-66662013000200007\& $\operatorname{lng}=\mathrm{es} \& \mathrm{t} \operatorname{lng}=\mathrm{es}$.

Yakman, G. y Lee, H. (2012). Exploring the exemplary STEAM education in the U.S. as a practical educational framework for Korea. Journal of the Korean Association for Science Education, 32(6), 1072-1086.

Zanotto, M. (2016). Comprensión lectora y aprendizaje de textos académicos: hacia una lectura estratégica en el campo de las ciencias sociales. En Bañales, G., Castelló, M. y Vega, N., Enseñar a leer y escribir en la educación superior. Propuestas educativas basadas en la investigación (pp. 29-51). SM México y Universidad Autónoma de Tamaulipas. http://www.fundacion-sm.org.mx/ sites/default/files/Ense\%C3\%B1ar\%20a\%20 leer $\% 20 y \% 20$ escribir.pdf 